\title{
MATURIDADE MORFOLÓGICA EM MACHOS DE MACROBRACHIUM JELSKII (MIERS, 1877)
}

\author{
Santos, I.N. ${ }^{1,{ }^{*}} \&$ Rocha, S.S. ${ }^{1}$ \\ ${ }^{1}$ Universidade Federal do Recôncavo da Bahia (UFRB) - Campus Cruz das Almas, CCAAB, \\ Laboratório de Bioecologia de Crustáceos. \\ *Autor correspondente: italonunes2009@gmail.com
}

Crescimento relativo é o estudo das relações entre dimensões de diferentes partes do corpo ou de órgãos, as quais podem aumentam segundo taxas iguais (isométricas) ou diferentes (alométricas), uma em relação à outra. Essas análises são de grande importância para determinar certos atributos biológicos, tais como o tamanho da primeira maturidade sexual. Macrobrachium jelskii é um camarão carídeo endêmico da América do Sul, com ocorrência na maioria das bacias hidrográficas do Brasil. A maturidade sexual desta espécie já foi estimada para as fêmeas, mas até o presente momento não há estimativas específicas para os machos. Desta forma, o objetivo deste trabalho foi estimar o tamanho médio da primeira maturação morfológica em machos de $M$. jelskii. Os espécimes foram coletados com peneiras, no açude do Engenho São João, município de Cruz das Almas, Bahia. Todos os animais tiveram o segundo pleópodo dissecado, seu comprimento da carapaça (CC) e comprimento (CAM) e largura (LAM) do apêndice masculino medidos em um estereomicroscópio dotado de software de medição. Os apêndices masculinos também foram classificados de acordo com sua morfologia em: "não desenvolvido"; "em desenvolvimento"; e "desenvolvido". Ao todo foram analisados 102 machos, cujo CC variou de 3,55 a 7,41 mm. As relações biométricas CC vs. CAM foram aquelas com maior $\mathrm{R}^{2}$ quando comparadas às CC vs. LAM, sendo, portanto, utilizadas no restante de nossas análises. Não houve significância nas relações biométricas quando considerado o estágio "não desenvolvido" do apêndice masculino. Desta forma, as relações CC vs. CAM dos estágios "em desenvolvimento e "desenvolvido" podem ser representadas pelas equações $y=0,4221 x-1,3592\left(R^{2}=0,72\right)$ e $y=0,2957 x-0,5086\left(R^{2}=0,84\right)$, respectivamente. O teste de ANCOVA detectou diferença significativa entre essas duas retas $(F=7,324 ; d f=1,0 ; p=0,008)$, demonstrando uma alteração na relação biométrica entre essas duas fases do desenvolvimento do apêndice masculino. Com isso, foi calculado o tamanho médio da primeira maturação morfométrica (L50\%), o qual foi estimado em 4,84 $\mathrm{mm}$. Além disso, constatou-se que durante a fase "em desenvolvimento" os indivíduos investem mais energia no crescimento do apêndice masculino em relação ao comprimento da carapaça. Por outro lado, quando o apêndice masculino se torna "totalmente desenvolvido" o investimento energético para o crescimento desta estrutura torna-se menos intenso.

Palavras-chave: apêndice masculino, Caridea, crescimento relativo, Bahia. 